\title{
Avaliação do desempenho dos estudantes da educação superior: a questão da eqüidade e
} obrigatoriedade no Provão e Enade* Giovanni Silva Paiva**

\section{Resumo}

A questão da qualidade do ensino no Brasil é enfatizada pela Lei de Diretrizes e Bases da Educação Nacional. A avaliação da educação superior tem destaque dentre as políticas educacionais com a criação de avaliações periódicas das instituições e cursos superiores, iniciada com a realização anual de exames nacionais. A avaliação do desempenho dos estudantes da educação brasileira é uma modalidade avaliativa implantada desde meados da década de 90. Inicialmente operacionalizada por meio do Exame Nacional de Cursos, que contou com oito aplicaç̃̃es anuais durante o período de 1996 a 2003, foi reformulada com a implantação do Exame Nacional de Desempenho dos Estudantes, parte integrante do Sistema Nacional de Avaliação da Educação Superior, instituído pela Lei $n^{\circ}$. 10.861/ 2004. As duas experiências avaliativas do desempenho acadêmico são objetos de observação minuciosa no presente trabalho, em face dos princípios de eqüidade e obrigatoriedade descritos na Constituição da República Federativa do Brasil.

Palavras-chave: Educação Superior. Avaliação do desempenho de estudantes. Eqüidade. Obrigatoriedade.

\section{Performance evaluation of the students in higher education: the matter of equity and mandatory in Provão and Enade Abstract}

The education quality issue in Brazil is emphasized by the Law of Guidelines and Bases of Education. The evaluation of higher education has been highlighted among the educational policies by the creation of periodic evaluations of institutions and higher education courses, which has started with the beginning of annual national examinations. The evaluation of the students' performance in Brazilian education is an evaluation method implemented since the mid-90. Initially, it was operated by the National Examination Course, and it was consisted of eight yearly exams during the period of 19962003, it was recast with the deployment of National Examination Performance of Students,

\footnotetext{
* Artigo elaborado como requisito parcial para avaliação de desempenho na disciplina Políticas de Educação e Gestão Educacional: Fundamentos, do curso de Mestrado em Educação da Universidade Católica de Brasília $\left(2^{\circ}\right.$ semestre letivo de 2007), sob a responsabilidade docente da Prof ${ }^{a}$. Dr ${ }^{a}$. Clélia de Freitas Capanema.

** Aluno especial do curso de Mestrado em Educação da Universidade Católica de Brasília, $2^{\circ}$ semestre letivo de 2007 e Técnico em Assuntos Educacionais do Instituto Nacional de Estudos e Pesquisas Educacionais Anísio Teixeira. E-mail: giovanni@inep.gov.br.
} 
which is part of the National System of Evaluation of the Higher Education, established by the Law no. 10.861/2004. The two evaluation experiences of academic performance are objects of thorough observation in this paper, based on the principles of equity and mandatory described in the Constitution of the Federative Republic of Brazil.

Keywords: Higher Education. Evaluation of the students' performance. Equity. Mandatory

\section{Evaluación del desempeño de los estudiantes en la enseñanza superior: la cuestión de la equidad $y$ obligatoriedad en Provão y Enade Resumen}

La cuestión de la calidad de la educación en el Brasil se destacó por la Ley de Directrices y Bases de Educación. La evaluación de la educación superior ha puesto de relieve entre las políticas de educación con la creación de evaluaciones periódicas de las instituciones y cursos de educación superior, que se inició con la celebración de los exámenes nacionales anuales. La evaluación del desempeño de los estudiantes en la educación brasileña es un modo de evaluación aplicado desde mediados-90.

Inicialmente realizada a través del Examen Nacional de Curso, a la que asistió con ocho solicitudes anvales durante el período de 1996 a 2003, ha sido refundida con el despliegue de Examen del Rendimiento Nacional de Estudiantes, que forma parte del Sistema Nacional de Evaluación de la Educación Superior, creada por la Ley No. 10.861/2004. Las dos experiencias de evaluación de desempeño académico son objetos de obsenvación en este exhaustivo trabajo, en vista de los principios de equidad y obligatoriedad descritos en la Constitución de la República Federativa del Brasil.

Palabras clave: Educación Superior. Evaluación del desempeño de los estudiantes. Equidad. Obligatoriedad.

\section{Introdução}

A Lei de Diretrizes e Bases da Educação Nacional (LDB), Lei n. 9.394 de 20 de dezembro de 1996 (BRASIL, 1996), enfatiza os processos de avaliação visando à meIhoria da qualidade do ensino, fornecendo parâmetros para a regulação do setor. Com a sanção da LDB, a avaliação da educação superior assume, então, lugar especial dentre as políticas educacionais, seja como norteadora de suas diretrizes mais amplas, seja como orientadora das ações concretas do próprio Ministério da Educação (MEC).

A Lei 9.131, de 24 de novembro de 1995 (BRASIL, 1995), cria o Conselho Nacional de Educação (CNE) e também estabelece como atribuições do MEC a formulação e avaliação da política nacional de educação, zelando pela qualidade do ensino. $\bigcirc$ mesmo instrumento legal também determinou a criação de um conjunto de avaliações periódicas das instituições e cursos superiores, com destaque para a realização anual de exames nacionais, pautados em conteúdos mínimos estabelecidos e previamente divulgados para cada curso. Os exames aferiam conhecimentos e competências adquiridos pelos alunos em fase de conclusão dos cursos de graduação, sendo os resultados divulgados anualmente pelo MEC.

Em cumprimento à legislação vigente, o MEC iniciou a aplicação de exames nacionais como parte da avaliação da educação superior brasileira. Aplicou, de forma pioneira, o Exame 
Nacional de Cursos (ENC) aos estudantes concluintes do segundo semestre letivo de 1996 dos cursos de administração, direito e engenharia civil. $\mathrm{ENC}$ foi objeto de severas críticas desde a sua concepção e estabelecimento de cronograma, sendo fundamentalmente questionado pela comunidade acadêmica em função do seu caráter obrigatório a todos os concluintes dos cursos de graduação, que seriam gradativamente inseridos no exame a cada ano.

O Sistema Nacional de Avaliação da Educação Superior (Sinaes), instituído pela Lei $\mathrm{n}^{\circ}$. 10.861, de 14 de abril de 2004 (BRASIL, 2004), apresentou um novo modelo de avaliação do desempenho acadêmico, como metodologia hábil à solução dos problemas imputados ao ENC. Desde 2004, quando foi instituído, ao Sinaes é atribuída a responsabilidade pela proposição e implantação de metodologias de avaliação que possam cumprir a atual política de avaliação da educação superior brasileira.

Exame Nacional de Desempenho dos Estudantes (Enade) é a parcela do Sinaes, em substituição ao ENC, que responde pela avaliação dos estudantes da educação superior. Trouxe, em sua proposta, inovações em relação ao ENC, inserindo os estudantes em fase inicial dos cursos de graduação, como forma de mensurar o conhecimento agregado ao estudante durante a sua formação acadêmica. Tem, contudo, a responsabilidade de corrigir os aspectos negativos apontados ao ENC.

Antes de qualquer mensuração de resultados do processo de avaliação do desempenho acadêmico é indispensável assegurar a participação de estudantes na avaliação pretendida. Nesse sentido, discutir a observação dos princípios de eqüidade e obrigatoriedade do ENC e Enade constitui um elemento fundamental para a compreensão de peculiaridades dessas modalidades avaliativas. $\bigcirc$ presente trabalho se propõe, então, a apresentar uma leitura do ENC e Enade, tendo como referencial a observação aos princípios de eqüidade e obrigatoriedade.

\section{O Exame Nacional de Cursos}

Desde meados da década de 90 o governo brasileiro vem implementando políticas públicas de avaliação com vistas à melhoria da qualidade da educação superior. A Lei n. 9.131, de 24 de novembro de 1995, criou o Exame Nacional de Cursos, popularmente conhecido como Provão', como metodologia de avaliação dos cursos de graduação pautada no desempenho dos respectivos concluintes. A aplicação pioneira do Provão ocorreu em novembro de 1996. Os cursos de administração, engenharia civil e direito foram os primeiros avaliados pelo Provão, mediante a participação de 55.526 concluintes no segundo semestre letivo daqueles cursos (INEP, 1997). Seguiu-se a sua aplicação no mês de junho dos anos subseqüentes, com a inserção anual e gradativa de novos cursos, culminando com o total de vinte e seis áreas avaliadas em 2003, último ano de sua aplicação. O texto legal especifica:

Art. $3^{\circ}$ Com vistas ao disposto na letra " $e^{\prime \prime}$ do $\S 2^{\circ}$ do art. $9^{\circ}$ da Lei $n^{\circ}$ 4.024, de 1961, com a redação dada pela presente Lei, o Ministério da Educação e do Desporto fará realizar avaliações periódicas das instituições e dos cursos de nível superior, fazendo uso de procedimentos e critérios abrangentes dos diversos fatores que determinam a qualidade e a eficiência das atividades de ensino, pesquisa e extensão.

$\S 1^{\circ}$ Os procedimentos a serem adotados para as avaliações a que

1 Será adotada neste artigo a denominação popular do Exame Nacional de Cursos - Provão.

Ensaio: aval. pol. públ. Educ., Rio de Janeiro, v. 16, n. 58, p. 31-46, jan./mar. 2008 
se refere o caput incluirão, necessariamente, a realização, a cada ano, de exames nacionais com base nos conteúdos mínimos estabelecidos para cada curso, previamente divulgados e destinados a aferir os conhecimentos e competências adquiridos pelos alunos em fase de conclusão dos cursos de graduação.

$\S 2^{\circ} \bigcirc$ Ministério da Educação e do Desporto divulgará, anualmente, o resultado das avaliações referidas no caput deste artigo, inclusive dos exames previstos no parágrafo anterior, informando o desempenho de cada curso, sem identificar nominalmente os alunos avaliados.

$\S 3^{\circ} \mathrm{A}$ realização de exame referido no $\S 1^{\circ}$ deste artigo é condição prévia para obtenção do diploma, mas constará do histórico escolar de cada aluno apenas o registro da data em que a ele se submeteu. $\S 4^{\circ}$ Os resultados individuais obtidos pelos alunos examinados não serão computados para sua aprovação, mas constarão de documento específico, emitido pelo Ministério da Educação e do Desporto, a ser fornecido exclusivamente a cada aluno.

$\S 5^{\circ} \mathrm{A}$ divulgação dos resultados dos exames, para fins diversos do instituído neste artigo, implicará responsabilidade para o agente, na forma da legislação pertinente.

$\S 6^{\circ} \mathrm{O}$ aluno poderá, sempre que julgar conveniente, submeter-se a novo exame, nos anos subseqüentes, fazendo jus a novo documento específico. $\S 7^{\circ} \mathrm{A}$ introdução dos exames nacionais, como um dos procedimentos para avaliação dos cursos de graduação, será efetuada gradativamente, a partir do ano seguinte à publicação da presente Lei, cabendo ao Ministro de Estado da Educação e do Desporto determinar os cursos a serem avaliados. (BRASIL, 1995, p. 19.257).

Merece destaque o fato de que as avaliações periódicas das instituições e dos cursos de nível superior, sob a responsabilidade do MEC, incluiriam a realização anual, a partir de 1996, de exames nacionais para aferir os conhecimentos e competências adquiridas pelos alunos em fase de conclusão dos cursos de graduação. Seria gradativa a introdução de exames nacionais como um dos procedimentos de avaliação dos cursos de graduação, cabendo ao Ministro de Estado da Educação a determinação dos cursos a serem avaliados a cada ano. A realização do exame ficou estabelecida como condição prévia à obtenção do diploma, sendo registrada no histórico escolar do aluno apenas a data em que a ele tenha se submetido. Ainda que não esteja expressamente declarado no texto legal, todos os alunos em fase de conclusão dos cursos de graduação estariam obrigados ao exame a partir da sanção da Lei $n^{\circ}$. 9.131/1995, na medida em que o registro do respectivo diploma estaria condicionado a participação no Provão.

Dois princípios são considerados, ainda que indiretamente, ao ser tratada a instituição do Provão: eqüidade e obrigatoriedade. $\bigcirc$ artigo $5^{\circ}$ da Constituição da República Federativa do Brasil (BRASIL, 1988) assegura a igualdade de todos perante a lei e enfatiza que a obrigatoriedade de fazer ou deixar de fazer alguma coisa decorre de especificação em lei. O Provão adotou o princípio da eqüidade na medida em que foi instituído para os cursos de graduação como método para a sua avaliação, mediante a participação dos alunos em fase de conclusão de cada 
curso. A observação ao princípio da obrigatoriedade foi garantida pela impossibilidade de dispensa, legalmente amparada, e pela restrição ao registro do diploma sem a comprovação de participação do concluinte no Provão.

A expedição da documentação inerente à conclusão de um curso de graduação tem prazos diferenciados, notadamente a emissão e registro do diploma, variando em função da organização acadêmica e localização da instituição de educação superior (IES). $\bigcirc$ certificado de conclusão do curso de graduação é o documento que permite ao egresso o exercício profissional antes do recebimento do próprio diploma, exceto para cursos da área de saúde, quando o registro junto aos órgãos fiscalizadores do exercício profissional requer a apresentação do diploma devidamente registrado. Assim, o estudante que, por qualquer razão, deixasse de se submeter ao Provão durante o ano de sua graduação, deveria fazê-lo no ano subseqüente, ficando sobrestado o registro do seu diploma. Confirma-se, aqui, a observação dos princípios de eqüidade e obrigatoriedade do Provão.

Não há registro de procedimentos administrativos adotados pelas autoridades para dispensa de estudantes da obrigatoriedade de participação no Provão. Casos excepcionais e isolados foram conduzidos por meio de ações judiciais. A mais significativa das ações judiciais ocorreu em 1998, quando a aplicação do Provão restou prejudicada na cidade de Belo Horizonte por força de liminar do Juiz da $12^{a}$ Vara da Justiça Federal de Minas Gerais. Essa ação judicial, sob a argumentação de possíveis prejuízos à avaliação dos estudantes em decorrência de greve nas universidades federais, culminou na excepcional dispensa pelo MEC de 3.906 estudantes inscritos para o exame naquela localidade (INEP, 1998).

Durante o período de sua execução o Provão movimentou a comunidade acadêmica, a mídia e a sociedade, grandes consumidores das informações por ele gerados. $\bigcirc$ Provão conviveu, inevitavelmente, com acertos e tropeços inerentes a qualquer experiência inovadora. Ao mencionar o clima de tranqüilidade e segurança que cercam as instituições de educação superior com bons resultados no Provão, Neiva e Collaço (2006, p. 197) afirmam que "certamente não haverá processo similar que não encontre resistências e críticas, oriundas das instituições e cursos cujos alunos não conseguem os mesmos resultados". O mesmo entusiasmo com que foi aplaudido, e reconhecido como experiência válida pelas IES e cursos com resultados no topo da escala de avaliação, o Provão foi combatido e, muitas vezes, repudiado por aqueles cujos resultados estavam no extremo oposto da mesma escala de avaliação.

É inconteste que o Provão despertou atenção e interesse da mídia para a questão da qualidade da educação superior brasileira. $\bigcirc$ Provão colocou, ainda que de forma latente, diante da sociedade, e principalmente dos estudantes da graduação e do ensino médio, importantes revelações quanto ao desempenho dos concluintes dos cursos de graduação acerca de questões do currículo do curso e da versatilidade para vencer os desafios do exercício profissional. Trouxe, também, importantes elementos para a reflexão e identificação de distorções do projeto pedagógico do curso e sua execução, visando à melhoria de sua qualidade do curso e, conseqüentemente, o alcance de melhor desempenho no Provão. 
Muitas são as críticas que ainda hoje persistem contra o Provão, mesmo após a sua revogação em 2004, quando foi substituído pelo Enade. A Comissão Especial de Avaliação da Educação Superior (CEA), designada pelas Portarias MEC/SESu ns. 11 e 19, de 28 de abril e 27 de maio de 2003, respectivamente, em seu relatório final, deu a conhecer:

O ENC tem como foco o Curso, em sua dimensão de ensino, e tem função classificatória, com vistas a construir bases para uma possível fiscalização, regulação e controle, por parte do Estado, baseada na lógica de que a qualidade de um curso é igual à qualidade de seus alunos. (INEP, 2007a, p. 24).

Ao dedicar especial atenção ao diagnóstico do marco legal e dos procedimentos de verificação e avaliação da educação superior, notadamente quando trata da síntese das contribuições das audiências públicas, a CEA manifesta:

Mas, é igualmente importante destacar que a extinção imediata do denominado Provão é por muitas entidades propugnada, tendo em vista a crítica ao fato de que subordinaria as orientações curriculares aos resultados obtidos, anualmente, pelos alunos concluintes, bem como ao questionamento de uma prova anual para os mesmos cursos e ainda a compulsoriedade da participação dos alunos. (INEP, 2007, p. 84).

O relatório final da CEA traz a proposição de nova sistemática de avaliação, constituindo o Sinaes, que busca assegurar "a integração das dimensões internas e externas, particular e global, somativo e formativo, quantitativo e qualitativo e os diversos objetos e objetivos da avaliação" (INEP, 2007a, p. 88).

\section{O Exame Nacional de Desempenho dos Estudantes}

A sanção da Lei n. 10.861/2004 (BRASIL, 2004), consolida o trabalho da CEA e, entre outras providências, determina que "a avaliação do desempenho dos estudantes dos cursos de graduação será realizada mediante a aplicação do Exame Nacional de Desempenho dos Estudantes - ENADE" (INEP, 2007a, p. 141), e revoga o art. $3^{\circ}$ da Lei n. 9.131/1995 (BRASIL, 1995), que trata da criação do Provão.

$\bigcirc \S 2^{\circ}$ do artigo $5^{\circ}$ da Lei n. 10.861/2004 estabelece que "o ENADE será aplicado periodicamente, admitida a utilização de procedimentos amostrais, aos alunos de todos os cursos de graduação ao final do primeiro e do último ano do curso" (INEP, 2007a, p. 142). $\bigcirc \S 5^{\circ}$ do mesmo artigo especifica o Enade como componente curricular obrigatório dos cursos de graduação. No histórico escolar do estudante será registrado o cumprimento desse componente curricular obrigatório, atestado pela sua efetiva participação ou, quando for o caso, dispensa oficial pelo MEC, na forma estabelecida em regulamento.

A análise dos dois parágrafos do artigo $5^{\circ}$ supramencionados suscita dúvidas acerca da adoção do princípio da eqüidade pelo Enade. Ao mesmo tempo em que o Enade é criado como componente curricular obrigatório de todos os cursos de graduação, é admitida a utilização de procedimentos amostrais ou considerada a possibilidade de dispensa oficial pelo MEC. O caráter ambíguo é observado ao ser tratada a obrigatoriedade a todos os cursos de graduação e, imediatamente, considerada a possibilidade de dispensa oficial pelo MEC. 
A CEA, em seu diagnóstico do marco legal e dos procedimentos de verificação e avaliação da educação superior, aponta o Provão como instrumento de avaliação extremamente oneroso, haja vista o aumento do número de instituições de educação superior observado nos últimos anos e, conseqüentemente, o "acréscimo ainda mais espetacular do número de cursos e alunos nos próximos anos" (INEP, 2007, p. 68). O Plano Nacional de Educação (2001) estabelece a expansão da oferta da educação superior para, pelo menos, 30\% da faixa etária de 18 a 24 anos, entre outros objetivos e metas, justificando o crescimento do número de cursos e matrículas nesse nível de ensino. A adoção de procedimentos amostrais na aplicação do Enade desponta em contraposição à obrigatoriedade do Provão a todos os concluintes dos cursos de graduação inseridos na avaliação a cada ano.

A tabela 1 ilustra a variação no número de cursos e estudantes inscritos para participação no Enade (2004 e 2007) e Provão (2001 e 1998) dos cursos de medicina veterinária e odontologia. Foram considerados cursos com freqüência mínima de três anos no Provão e participação em duas aplicações do Enade, favorecendo a análise relativa a um triênio.

Tabela 1 - Número de cursos e de estudantes inscritos em medicina veterinária e odontologia.

\begin{tabular}{|l|c|c|c|c|c|c|c|c|}
\hline \multirow{2}{*}{ Área } & \multicolumn{3}{|c|}{ Número de cursos } & \multicolumn{3}{c|}{ Número de inscritos } \\
\cline { 2 - 10 } & \multicolumn{2}{|c|}{ Enade } & \multicolumn{2}{c|}{ Provão } & \multicolumn{2}{c|}{ Enade } & \multicolumn{2}{c|}{ Provão } \\
\cline { 2 - 10 } & 2007 & 2004 & 2001 & 1998 & 2007 & 2004 & 2001 & 1998 \\
\hline Medicina Veterinária & 140 & 114 & 59 & 39 & 16.224 & 10.906 & 3.396 & 2.386 \\
\hline Odontologia & 176 & 155 & 104 & 86 & 18.050 & 15.014 & 9.215 & 7.864 \\
\hline
\end{tabular}

Fonte: INEP (2007a).

Da análise dos dados apresentados na tabela 1 é possível inferir que o número de cursos de medicina veterinária avaliados pelo Provão tem crescimento de $51,3 \%$, considerando o intervalo de três anos, enquanto o total de inscritos varia em 42,3\%. No Enade, considerando também um intervalo de três anos, o número de cursos de medicina veterinária tem variação bem menor - $22,8 \%$, enquanto os inscritos variam em 48,8\%. No intervalo 2004/2007 a variação no número de estudantes de medicina veterinária inscritos no Enade cresce mais que proporcionalmente ao número de cursos. A mesma tendência é observada para o curso de odontologia. A tendência de crescimento do número de cursos e estudantes afeta, da mesma forma, qualquer modalidade avaliativa do desempenho acadêmico, seja ela Provão ou Enade.

A variação no número de cursos e estudantes é fator relevante para qualquer modalidade avaliativa, fundamentalmente ao ser considerada a viabilidade econômica de sua realização. Nesse sentido, a proposição de procedimentos amostrais para o Enade visa ao equacionamento da viabilidade econômica em face do crescimento do número de estudantes habilitados à avaliação do desempenho acadêmico. 
Segundo Ferreira (1986, p. 675), eqüidade é a "disposição de reconhecer igualmente o direito de cada um". Todos os estudantes dos cursos de graduação têm o Enade como componente curricular obrigatório e a seleção aleatória e representativa de alguns estudantes para participação no Enade sugere direito à dispensa para alguns, revelando a quebra do princípio da eqüidade. Se a todos os ingressantes e concluintes dos cursos avaliados é assegurada a participação no Enade, independentemente da seleção pelos procedimentos amostrais, o mesmo não pode ser dito com relação ao direito à dispensa. $\bigcirc$ artigo $6^{\circ} \mathrm{da}$ Portaria INEP n. 107, de 22 de julho de 2004 (INEP, 2007a, p. 160, grifo nosso), determina que "os estudantes selecionados pelo INEP para participar do Enade deverão comparecer e realizar, obrigatoriamente, o Exame no dia e hora definidos em calendário[...]".

princípio da eqüidade é latente nas atividades anuais de organização do Enade. As Portarias do MEC e do Instituto Nacional de Estudos e Pesquisas Educacionais Anísio Teixeira (INEP) ${ }^{2}$, que estabelecem as diretrizes para operacionalização do exame, determinam que a aplicação do exame será realizada a uma amostra representativa de estudantes do final do primeiro e último ano do curso de graduação. Esses instrumentos legais deixam claro que alguns estudantes serão dispensados, imputando ao INEP a responsabilidade pela definição e aplicação dos critérios técnicos para a seleção de estudantes que representarão o próprio curso de graduação nessa modalidade avaliativa. Se necessariamente alguns estudantes serão beneficiados com a dispensa da obrigatoriedade de participação no Enade, é clara a inobservância ao princípio da eqüidade.

Os percalços enfrentados pela experiência pioneira do Enade 2004 suscitaram novos elementos que caracterizam sobremaneira a quebra do princípio da eqüidade. A programação do Enade 2004 para o dia 7 de novembro daquele ano trouxe à discussão questões relativas ao atraso na expedição de diplomas de concluintes do primeiro semestre letivo do mesmo ano. A edição da Portaria MEC n. 2.648, de 31 de agosto de 2004, dispensou, antes da primeira aplicação do Enade, os estudantes que colaram grau até o dia 19 de setembro de 2004, além daqueles que estavam matriculados e cursando atividades curriculares fora do País na data de realização do exame, em instituições conveniadas com a IES de origem do estudante. A programação do Enade para o mês de novembro de cada ano instituiu esse procedimento de dispensa prévia para as demais edições do exame, passando a constar das portarias de instituição do Enade a cada ano.

A periodicidade de aplicação do Enade é trienal, o que significa dizer que a segunda avaliação do desempenho acadêmico dos estudantes de um curso de graduação somente ocorrerá depois de decorridos três anos. A impossibilidade de participação no Enade em 2006 por um possível concluinte de administração, por exemplo, decorrente de força maior ou de qualquer outra eventualidade, inviabiliza a conclusão do próprio curso de graduação, haja vista ser o Enade um componente curricular obrigatório. A rigor, o estudante aguardará por três anos a próxima avaliação do seu curso de graduação pelo Enade, momento em que poderá cumprir o componente curricular obrigatório, permitindo a expedição de documentação inerente à conclusão do próprio curso de graduação. Durante esse período sequer poderá exercer provisoriamente a sua profissão,

2 Portaria MEC $n^{\circ}$. 2.051, de 9 de julho de 2004, Portaria INEP n. 107, de 22 de julho de 2004, e Portaria INEP $n^{\circ} .108$, de 22 de julho de 2004. 
uma vez que não concluiu o seu curso de graduação, ainda que todos os demais componentes curriculares tenham sido cumpridos junto à instituição de educação superior.

Os ingressantes e concluintes dos cursos de graduação avaliados a cada ano pelo Enade contam, também, com outra possibilidade de dispensa oficial pelo MEC. Desde 2005, após a primeira aplicação do Enade em 2004, anualmente é instituída pelo MEC uma Comissão Especial ${ }^{3}$ com o objetivo de analisar os diversos pedidos de dispensa ao Enade, pautados nas diferentes justificativas de ausência à prova. Anualmente são apresentadas orientações para submissão de pedidos de dispensa ao Enade por meio da página do INEP na internet ${ }^{4}$. Apenas os pleitos deferidos pela Comissão Especial são publicamente conhecidos. No Enade 2004 foram deferidos 1.174 pedidos de dispensa. $\bigcirc$ número de dispensas atingiu o limite de 5.286 no Enade 2005. Já o Enade 2006 registra o total de 3.495 dispensas, sempre divulgadas por meio da edição de Portarias ${ }^{5}$ com esse fim específico.

As quatro edições do Enade foram levadas a termo sempre no mês de novembro de cada ano. Exceto no ano de 2004, quando a realização do Enade foi postergada em função da sanção da Lei n ${ }^{\circ} 10.861 / 2004$ (BRASIL, 2004), no mês de abril - instrumento legal de instituição do Enade, não são conhecidas justificativas para a sua realização durante o mês de novembro de cada ano. É inquestionável que esse procedimento leva à dispensa os estudantes que concluem o curso de graduação, objeto de avaliação, durante o primeiro semestre letivo de cada ano. Os estudantes nessa situação não podem ser penalizados com o atraso na expedição do respectivo diploma em função de procedimentos administrativos que levam à realização do Enade em período diferente do das suas atividades acadêmicas. Todos os meios já descritos para obtenção de dispensa ao Enade levam ao questionamento do princípio da obrigatoriedade para esse componente curricular obrigatório dos cursos de graduação.

A Comissão Nacional de Avaliação da Educação Superior (CONAES), órgão colegiado instituído pela Lei 10.861/2004, após a realização de estudos técnicos que permitem o agrupamento de cursos correlatos e a conciliação de orçamento e projeção de número de estudantes aptos à avaliação do desempenho acadêmico, submete à aprovação do Ministro de Estado da Educação a relação dos cursos a cujos estudantes será aplicado o Enade. $\bigcirc$ MEC determina, assim, os cursos de graduação que serão avaliados a cada ano, obsenvada a periodicidade trienal de realização do Enade. Os estudantes de cursos não selecionados pelo MEC são dispensados do Enade naquele ano. Todos os estudantes dos cursos selecionados, então, têm o Enade como componente curricular obrigatório, a ser cumprido durante o ano de aplicação da prova para o respectivo curso.

A legislação vigente especifica os critérios de habilitação ao Enade. Estabelece que sejam caracterizados como estudantes de final do primeiro ano aqueles que, até a data inicial do processo de inscrições, tenham cumprido entre $7 \%$ e $22 \%$ (inclusive) da carga

3 Portarias MEC nº. 4.036, 169 e 46, de 8/12/2004, 18/1/2006 e 15/1/2007, respectivamente.

4 Disponível em: http://www.inep.gov.br.

5 ENADE 2004 - Portarias MEC nºs. 218, 778, 1.397, 1862 e 2.592, de 25/1/2005, 9/3/2005, 28/4/2005, 1/6/2005 e 22/7/2005, respectivamente. ENADE 2005 - Portarias MEC n's. 805 e 992, de 28/3/2006 e 8/5/2006, respectivamente. ENADE 2006 - Portarias MEC ns. 224, 437 e 739, de 7/3/2007, 10/5/2007 e 25/7/2007, respectivamente. 
horária mínima do currículo do curso de graduação. Por outro lado, estabelece que sejam caracterizados como estudantes do último ano do curso aqueles que, na mesma data de referência, tenham cumprido pelo menos $80 \%$ da carga horária mínima do próprio curso ou possam concluí-lo durante o ano letivo de realização do Enade. Todo estudante de um curso avaliado que não satisfaça aos critérios para habilitação ao Enade estaria, em tese, dispensado da obrigatoriedade do exame. A instituição de educação superior, então, para esses estudantes, procederia ao registro no histórico escolar da situação de dispensa, nos termos da Lei $n^{\circ}$. 10.861/2004. Esses estudantes, a rigor, jamais estariam obrigados ao Enade, descaracterizando a aplicação do princípio de obrigatoriedade.

As edições do Enade de 2005, 2006 e 2007 foram caracterizadas pela oportunidade de regularização da situação do componente curricular obrigatório aos estudantes que, estando obrigados ao exame, não puderam fazê-lo à época oportuna. A esses estudantes, contudo, é exigida a participação no exame, respondendo apenas às questões de formação geral, que compõem $25 \%$ da prova aplicada a cada ano para avaliação dos diversos cursos. Não há eqüidade se alguns estudantes participam de uma prova com abrangência diferenciada de outros que, estando em situação irregular com a mesma obrigação legal, cumprem apenas parte do dever.

A análise de estatísticas divulgadas pelo Inep revela que o Enade também registra índices de abstenção a cada aplicação de prova. O significado da perda decorrente da abstenção ao exame ainda não foi objeto de estudo e divulgação, nem tampouco o custo operacional da nova oportunidade de participação no Enade por estudantes em situação irregular junto ao componente curricular obrigatório. Da mesma forma, não é conhecida a representatividade da população que a cada ano deixa de participar da avaliação em função de critérios prévios de dispensa. É incontestável que essas ocorrências permitem o questionamento da observação aos princípios de eqüidade e obrigatoriedade pelo Enade, enquanto metodologia de avaliação do desempenho dos estudantes dos cursos de graduação no Brasil.

Mesmo após o encerramento do primeiro ciclo do Enade diversas áreas do conhecimento ainda não foram inseridas nessa modalidade avaliativa. Dentre elas é possível a identificação da antropologia social (com 17 cursos no Brasil), ciência política (53), estatística (52), geofísica (11), geologia (44), meteorologia (16), oceanografia (17) e relações internacionais (200). Os estudantes dessas áreas do conhecimento foram oficialmente dispensados do Enade em todas as edições do exame - 2004 a 2007, mesmo sendo este um componente curricular obrigatório. Não obstante as razões políticas e técnicas que justificam a omissão, não há, mais uma vez, observação aos princípios da eqüidade e obrigatoriedade do Enade a todos os cursos de graduação e respectivos estudantes.

A título de ilustração e finalizando as observações acerca dos princípios da eqüidade e obrigatoriedade, destaca-se que a questão ora abordada também é objeto de observação e análise por diversos estudiosos e atores envolvidos no processo de avaliação da educação superior brasileira. Mais particularmente, em relação ao Enade, Figueiredo ${ }^{6}$ (2007) afirma que "o ENADE não é o sistema completo de avaliação, não é feito por todos os alunos e alguns, muitas vezes, não têm compromisso com o

6 Hermes Figueiredo - Presidente do Sindicato das Entidades Mantenedoras dos Estabelecimentos de Ensino Superior do Estado de São Paulo. 
resultado". Sasaki (2006, p. 2) ressalta que "muitos pontos do processo de avaliação devem ser revistos pelo MEC para uma avaliação completa" e que

Há muita controvérsia sobre o Enade, principalmente quando se trata de que os alunos que realizam a prova quando ingressam no curso não são os mesmos que fazem à próxima edição do Enade, pois, em alguns casos, já estão formados. [...] Acredito que o processo de avaliação na educação brasileira criou traumas quando se trata de obrigar o aluno a realizar mais uma prova. Ao mesmo tempo, acredito que cabe a cada instituição realizar um trabalho de conscientização sobre a importância de se fazer o Enade. O diálogo entre dirigentes e lideranças estudantis é imprescindível nesse processo. [...] o Enade inovou na ampliação de questões que envolvem conhecimentos gerais, além das específicas; as provas são feitas com alunos no início e final dos cursos; é amostral e feito por sorteio, ou seja, a cada triênio são escolhidos os cursos e realizado o respectivo sorteio dos alunos, diferente do Provão que obrigava todos os alunos a realizarem a prova. [...].

Collaço e Neiva (2007), ao abordarem a questão da inclusão social, questionam a utilização dos resultados do Enade, parte da avaliação proposta pelo Sinaes, como critério na concessão de financiamento a estudantes regularmente matriculados em cursos superiores não gratuitos e com avaliação positiva. Não mencionam, contudo, a periodicidade trienal do Enade, fato que pode estender a dificuldade de acesso ao FIES por estudantes de cursos com baixo desempenho no Enade. Na abordagem da obrigatoriedade de participação no Enade pelos estudantes selecionados os autores levantam situações conduzidas no âmbito do Poder Judiciário e revelam:

Sob o estímulo dos agentes do MEC, não raro equivocados na interpretação e aplicação das leis educacionais, algumas instituições de ensino superior têm-se recusado a conceder colação de grau e a entregar o correspondente diploma de graduação a alunos que, sorteados pelas roletas do INEP, se recusam a participar do ENADE. Trata-se de um ato abominável, na medida em que essa recusa despropositada implica aplicação de sanção não prevista em lei. Recente acórdão da Quinta Turma do Tribunal Regional da $1^{a}$ Região, Relator o desembargador federal João Batista Moreira (MAS 2005.33.00.010622-3/BA; DJ de 23.1 1.2006), que resume a jurisprudência que se vai firmando nos demais tribunais regionais federais, vale como exemplo para que seja dado um "pára" nessas atitudes tão incompreensíveis quanto nefastas. Diz o acórdão que "a Lei 10.861/2004, que institui o Sistema Nacional de Avaliação da Educação Superior, no $\S 2^{\circ}$ do art. 10, prevê cabimento de sanções tão-somente à instituição pela não-inscrição de alunos habilitados ao exame. Não há previsão legal de sanções aos alunos inscritos que deixarem de participar". A isso acrescenta: "A necessidade de inscrição, no histórico escolar, da situação do estudante, mediante certificação de efetiva participação no exame ou de dispensa oficial pelo Ministério da Educação ( $5^{\circ}$ do art. $5^{\circ}$ da Lei $\left.10.861 / 04\right)$, visa apenas a

7 Karen Sasaki - Coordenadora de Ensino a Distância da Faculdade de Tecnologia e Ciências (FTC) - Salvador/BA. 
compelir o estudante convocado a colaborar com o Poder Público no procedimento de avaliação do ensino nacional". [...] "O descumprimento de tal obrigação, pela inobservância da convocação, não pode ensejar óbice à concessão do diploma, posto que totalmente desproporcional ao dever inadimplido e sem qualquer previsão legal específica". Em outras palavras, está dito o seguinte na decisão judicial: uma lei que não fixa uma sanção para um determinado comportamento desejável e não satisfeito é, como dizem os que operam com o Direito, uma faca sem lâmina [...]. (COLLAÇO; NEIVA, 2007, p. 2).

Poder Judiciário conta com outras interpretações da legislação vigente e que também são publicamente conhecidas:

Estudante que não fez o Exame Nacional de Desempenho de Estudantes (Enade) perde o direito de se graduar e receber diploma, até acertar a situação. O entendimento é do ministro Raphael de Barros Monteiro Filho, presidente do Superior Tribunal de Justiça. O ministro negou o pedido do estudante Dijalma Carvalho Costa Júnior, que não fez a prova Enade e, por isso, não conseguiu colar grau. Para o presidente do STJ, faltou argumento para justificar o pedido. (CONSULTOR JURÍDICO, 2007).

As opiniões aqui apresentadas revelam a dificuldade de estabelecimento de consenso em relação aos princípios de eqüidade e obrigatoriedade do Enade, parte da política de avaliação da educação superior vigente no País. As diversas manifestações tratam, ainda que de forma tangencial, o ponto central do presente trabalho e confirmam a impossibilidade de se esgotar o tema ora discutido.

\section{Considerações finais}

A implantação de políticas públicas de avaliação da educação superior brasileira é atividade que, indiscutivelmente, desencadeia manifestações favoráveis e críticas severas. Ajustes são necessários e identificados ao longo do processo de implantação e execução de políticas públicas. A permanente avaliação das políiticas públicas, bem como os ajustes que daí decorrerem, asseguram o sucesso e manutenção das políticas públicas implantadas pelo Estado. A avaliação do desempenho acadêmico, enquanto componente da políitica pública de avaliação da educação superior brasileira, caracterizada pela aplicação de exames nacionais, não é atividade de menor complexidade. $\bigcirc$ seu sucesso depende, sobremaneira, do compromisso de todos os atores envolvidos no processo. Os estudantes destacam-se como atores de maior importância quando a avaliação em questão é a do desempenho acadêmico.

A aplicação de exames nacionais pressupõe a efetiva participação de estudantes dos cursos avaliados, assegurando confiabilidade aos resultados apurados. $\bigcirc$ princípio da obrigatoriedade, embora com uma conotação autoritária, é a garantia de sucesso na avaliação do desempenho de estudantes, embora não possa assegurar resultados confiáveis. $\bigcirc$ princípio da eqüidade, contudo, ameniza o caráter autoritário da obrigatoriedade de participação em exames nacionais. A aplicação concomitante dos dois princípios facilita o sucesso na participação dos estudantes em exames com essas características. 
A aplicação de exames nacionais para avaliação da educação superior no Brasil foi iniciada com o Provão e, atualmente, é desenvolvida por meio do Enade. Este, ao substituir o Provão em 2004, trouxe em sua proposta a responsabilidade de inovações e correções dos desacertos imputados ao primeiro. A questão da obrigatoriedade de participação no Provão como condição prévia ao registro do diploma foi um dos aspectos mais criticados durante os oito anos de sua aplicação. O anseio pela extinção dessa condição prévia ao registro do diploma desencadeou obrigatoriedade ainda mais severa. Se antes, apenas o registro do diploma estava condicionado ao Provão, dentre as atividades inerentes à conclusão do curso superior, hoje a própria conclusão da graduação depende do cumprimento de um componente curricular obrigatório que não está sob a responsabilidade da instituição de educação superior: o Enade.

Os registros das experiências de aplicação do Provão, durante o período de 1996 a 2003, apontam para a observação aos princípios de eqüidade e obrigatoriedade dos concluintes dos cursos superiores de graduação sob avaliação. As diferentes áreas do conhecimento, uma vez inseridas nessa modalidade avaliativa, tiveram a sua participação assegurada em todas as aplicações subseqüentes. Os concluintes, ainda que de forma imperativa, não deixaram de comparecer à prova.

O Enade, por sua vez, ao adotar procedimentos de amostragem de ingressantes e concluintes dos cursos que avalia com periodicidade trienal, quebra a observação ao princípio da eqüidade. Ainda que todos os estudantes dos cursos de graduação tenham o Enade como componente curricular obrigatório, nem todos são compelidos a participar do exame. A adoção de diversos procedimentos de dispensa permite o questionamento acerca da eqüidade e obrigatoriedade aplicada ao Enade. Neiva e Collaço (2006, p. 229) apontam pelo menos quatro fragilidades imputadas à avaliação de cursos de graduação realizada por meio de procedimentos amostrais e por períodos, com perspicaz alusão à aplicação dos princípios de eqüidade e obrigatoriedade pelo Enade:

a) a primeira é a de que nem sempre o aluno que fizer o exame no final do primeiro ano do curso estará em condições de prestálo no último, mesmo conhecido o argumento de que, estatisticamente, isso é irrelevante; b) a segunda é a de que exames periódicos não permitem acompanhamento continuado, e o caráter amostral pode muito bem deslocá-lo para a avaliação muitos e muitos anos depois; c) a terceira é a de que o sorteio é uma forma lotérica que a nada leva, pelo menos de um ponto de vista pedagógico, que é um dos valores maiores que informa o processo de avaliação; d) a quarta é a de que não se aplica aos sistemas estaduais de ensino, vale dizer, às instituições de ensino superior (estaduais e municipais) por eles controladas, o que, [...] dificulta sobremaneira a realização do sonho de um "sistema nacional de avaliação". Logo, o ingrediente avaliação do "produto final" gerado por uma instituição de ensino superior deixou de ser ingrediente nacional. 
As diferentes manifestações sobre a observação aos princípios de eqüidade e obrigatoriedade pelas experiências avaliativas do desempenho acadêmico da educação superior brasileira, aqui expostas, têm por objetivo despertar o interesse de estudiosos para uma análise minuciosa, desencadeando a ampla discussão sobre a matéria. Longe da pretensão de esgotar o assunto, este trabalho chama a atenção para aspectos que, muitas vezes, são ofuscados por questões de maior repercussão, como os resultados e inferências que advêm da análise do desempenho acadêmico e culminam com a atribuição de conceitos aos cursos avaliados.

\section{Referências}

BRASIL. Constituição (1988). Constituição da República Federativa do Brasil 1988. Disponível em: <http://www6.senado.gov.br/con1988/CON1988_05.10.1988/ CON1988.htm >. Acesso em: 8 out. 2007.

. Lei $n^{\circ}$. 9.131, de 24 de novembro de 1995. Altera dispositivos da Lei $n^{\circ}$. 4.024, de 20 de dezembro de 1961, e dá outras providências. Diário Oficial [da República Federativa do Brasil], Brasília, DF, p. 19.257, 25 nov. 1995. Edição extra.

. Lei n. 9.394, de 20 de dezembro de 1996. Estabelece as Diretrizes e Bases da Educação Nacional. Diário Oficial [da República Federativa do Brasil], Brasília, DF, 23 dez. 1996. Disponível em: <http://www.planalto.gov.br/ccivil/LEIS/ L9394.htm>. Acesso em: 8 out. 2007.

BRASIL. Lei $n^{\circ}$. 10.172, de 9 de janeiro de 2001. Aprova o Plano Nacional de Educação e dá outras providências. Diário Oficial [da República Federativa do Brasil], Brasília, DF, 11 jan. 2001. Disponível em: <https://www.planalto.gov.br/ ccivil_03/leis/leis_2001/110172.htm >. Acesso em: 12 nov. 2007.

. Lei $n^{\circ}$. 10.861, de 14 de abril de 2004. Institui o Sistema Nacional de Avaliação da Educação Superior - Sinaes - e dá outras providências. Diário Oficial [da República Federativa do Brasil], Brasília, DF, n. 72, p. 3-4, 15 abr. 2004.

. Portaria $n^{\circ} 2.448$, de 31 de agosto de 2004. Diário Oficial [da República Federativa do Brasil], Brasília, DF, 1 set. 2004. Seção 1, p. 17.

COLLAÇO, F. R.; NEIVA, C. C. O FIES, o ENADE e a má conduta dos agentes do Ministério da Educação. Disponível em: <www.educonsult.com.br/doujur/ ENADE_FIES_ARTIGO.doc >. Acesso em: 14 nov. 2007.

FERREIRA, A. B. H. Novo dicionário da língua portuguesa. 2. ed. rev. e aum. Rio de Janeiro: Nova Fronteira, 1986. 
FIGUEIREDO, H. Cursos reprovados no Enade oferecem bolsas do ProUni. G1, São Paulo, 31 jul. 2007. Disponível em: <http://g1.globo.com/Noticias/Nestibular/ 0,,MUL80911-5604,00.html >. Acesso em: 13 nov. 2007.

INEP. Exame Nacional de Cursos 1996: síntese. Brasília, DF, 1997.

. Exame Nacional de Cursos: relatório-síntese 1998. Brasília, DF, 1998.

Exame Nacional de Cursos (ENC-Provão): relatório-síntese 2001.

Brasília, DF, 2001. Disponível em: <http://www.inep.gov.br/superior/provao/ sintese/sintese2001.htm>. Acesso em: 12 nov. 2007.

INEP. ENADE 2004: relatório-síntese Medicina Veterinária. Brasília, DF, 2004a. Disponível em: <http://www.inep.gov.br/download/superior/enade/Relatorio/ Relatorio_area_Medicina_Veterinaria.pdf>. Acesso em: 12 nov. 2007.

ENADE 2004: relatório-síntese Odontologia. Brasília, DF, 2004b.

Disponível em: <http://www.inep.gov.br/download/superior/enade/Relatorio/ Relatorio_area_Odontologia.pdf $>$. Acesso em: 12 nov. 2007.

. ENADE 2007: informações ENADE 2007. Brasília, DF, 2007a. Disponível em: <http://www.inep.gov.br/download/imprensa/2007/

Tabelas_ENADE2007.pdf $>$. Acesso em: 12 nov. 2007.

. SINAES: da concepção à regulamentação. Brasília, DF, 2007b.

NEIVA, C. C.; COLLAÇO, F. R. Temas atuais de educação superior. Brasília, DF, ABMES, 2006.

REQUISITO obrigatório: estudante que não fez o Enade não tem direito a diploma. Consultor Jurídico, São Paulo, 18 jun. 2007. Disponível em: <http:// conjur.com.br/static/text/57659? display_mode=print>. Acesso em: 14 nov. 2007.

SASAKI, K. ENADE: uma avaliação adequada ao ensino superior?. Folha Dirigida, Rio de Janeiro, 21 ago. 2006. Clipping Educacional. Disponível em: <http:// www.sbc.org.br/index.php? language $=1$ \&subject $=1$ \& content $=$ news\&id $=5455>$. Acesso em: 13 nov. 2007.

Recebido em: 29/11/2007

Aceito para publicação em: 07/01/2008 